\title{
Temporal dimensions of reported life satisfaction in a low-income, agricultural environment
}

\author{
$\underline{\text { Helen Adams }}^{1}$, Andrew Reid Bell ${ }^{2}$ and $\underline{M d}$. Ehsanul Haque Tamal $^{3}$
}

\begin{abstract}
Improving quality of life of farmers in rapidly changing rural economies remains a challenge. In low income settings, agricultural lean seasons lead to a fall in consumption and nutrition that affect longer term well-being trajectories. However, human well-being goes beyond material wealth, and increasingly subjective well-being is measured to reflect whether personal objectives are being met across a range of life domains. However, resource constraints mean surveys are usually carried out once a year, or at most, once a season. Here, we investigate whether life satisfaction reported annually is representative of assessments throughout the year, with a focus on the influence of the agricultural cycle on scores. We do so using data from a novel, mobile phone-based survey that collected 10,032 observations of life satisfaction reported weekly for one calendar year in land-owning farmers in Bangladesh. The data show that most individuals report stable and midrange life satisfaction. Smaller groups show consistently low, consistently high, or fluctuating levels of satisfaction. Using a cluster analysis, we define natural groups based on levels and stability of satisfaction. Social-demographics as well as material wealth predict membership of these groups showing the relative and culturally embedded nature of subjective well-being. Agricultural activities throughout the year are significantly associated with reported life satisfaction, but not always consistent with low seasons: land preparation and harvest are associated with increased life satisfaction; weeding and irrigation are associated with lower satisfaction. Furthermore, we show that the periods of activity during the agricultural cycle most likely to be associated with satisfaction vary depending on whether the individual reports high, low, or variable life satisfaction. Thus, we suggest, to improve well-being in low-income rural areas, analysis should include people's propensity to be satisfied, as this alters sensitivity to changes in other life domains.
\end{abstract}

Key Words: android ODK; Bangladesh; ecosystem services; microtasks for micropayments; seasonality; subjective well-being

\section{INTRODUCTION}

Rural populations in the global south persist in rapidly changing and often increasingly difficult social, economic, and environmental conditions (Hossain et al. 2016, Rigg et al. 2018). Although migration to urban centers, remittances, and off-farm labor are increasingly significant in sustaining rural life, agriculture remains the linchpin of many rural economies (World Bank Group 2016). In this setting, coping strategies to smooth consumption over seasonal agricultural low periods undermine longer term well-being trajectories (Dercon and Krishnan 2000, Hulme and Shepard 2003). However, income and consumption are not the only determinants of well-being. Our objective in this paper is to understand how subjective elements of well-being vary with these agricultural cycles and if measuring well-being over the agricultural calendar can tell us anything about the nature and predictors of subjective well-being.

There are many reasons why well-being is influenced by the seasons. Predictable seasonal low periods are caused by lack of food crops for subsistence, combined with the inability of households to transfer assets between seasons (Khandker 2012, Basu and Wong 2015), and increases in food prices for the landless (Becquey et al. 2012). However, drivers of seasonality are not always related to agriculture. The rainy season can lead to certain activities becoming more difficult, for example, firewood collection, cooking with firewood, and transportation such as rickshaw pulling (Adams et al. 2013, Becquey et al. 2012). Furthermore, seasonality in consumption can be caused by annual expenditures on festivals and weddings (Jolliffe and Serajuddin 2018) and seasonality of diseases such as cholera can influence consumption through out of pocket costs for healthcare (Baracchini et al. 2017).

Yet, well-being is multidimensional and is generated by a range of conditions beyond income. Since the early 2000s, analyses of poverty have increasingly put material well-being in the context of the wider human experience (e.g., Sen 2001, Gough and McGregor 2007, OECD 2013). In doing so, they acknowledge that policies and programs target material conditions of the poor not for their own end, but to increase satisfaction with life (variously conceptualized as welfare or happiness) and that material conditions alone do not create the conditions necessary for this "good life." Thus, academics have begun to measure subjective well-being (SWB), a person's assessment of their own life satisfaction, and to investigate the contribution of different life domains to satisfaction, especially nonmaterial dimensions such as a sense of community, equality, security, or access to decision making over one's own life (McGregor et al. 2015).

In this paper, we analyze seasonal variations in subjective wellbeing. We analyze weekly reported life satisfaction (RLS) scores in a group of 480 land-owning farmers in Rangpur District in Bangladesh. This is an area where livelihoods are highly seasonal and driven by the presence or absence of the monsoon rains (Khandker 2012). Further, Bangladesh, while one of the poorest countries in the world, exhibits sometimes contradictory wellbeing characteristics. Although material poverty is generally matched by low levels of reported life satisfaction and low positive affect (Asadullah and Chaudhury 2012, Mahmud and Sawada 2018), the nation is associated with happiness levels higher than 
the material conditions of its population might predict. People adapt life expectations to the reality they face (Clark 2012), in a process known as adaptive preference formation (Sen 2001), and as such approaches based in subjective well-being may produce distorted representations of reality (Teschl and Comim 2005). However, this apparent contradiction may also reflect that the Bangladeshi poor prioritize a range of life domains beyond income (Camfield et al. 2010). Further, objective development indicators are also inconsistent; for example, Bangladesh shows lower birth rate and mortality for its levels of poverty (Chowdhury et al. 2013).

We make both a methodological and a substantive contribution. Our methodological contribution is to measure subjective wellbeing on high temporal timescales in a low income, rural setting facilitated by a novel, mobile phone-based data collection technique. In doing so, we provide the longer term temporal context for one-time or annual reported life satisfaction scores and show that they are, in general, representative of what the respondent would have reported at any other time across the year. Substantively, we show whether life satisfaction exhibits seasonal variation in farmers, and if so, whether its patterns echo the agricultural seasons. We show that agricultural activities are significantly associated with life satisfaction, but not in ways completely consistent with "hungry" seasons.

We go further to show the benefits of measuring subjective wellbeing as a distribution rather than a point estimate. Using cluster analysis, we group respondents by the characteristics of their reported life satisfaction: the strength of their satisfaction and the stability of their scores. First, we predict membership of these groups, and show that there are certain socio-demographic characteristics that increase the likelihood of the individual reporting high or low satisfaction with life. Second, we show that the life satisfaction of someone who is consistently satisfied shows a different sensitivity to objective changes in the agricultural calendar to someone who is consistently dissatisfied, or whose satisfaction fluctuates throughout the year.

\section{SUBJECTIVE WELL-BEING IN LOW INCOME SETTINGS}

Subjective well-being is a measure of how people cognitively assess their own lives representing "all of the various evaluations, positive and negative, that people make of their lives, and the affective reactions to their experiences" (OECD 2013:10) and, thus, represents our ability to self-actualize, i.e., to be masters of our own destiny (Ryan and Deci 2000). Subjective well-being is usually articulated as an aggregate of components: cognitive (selfassessment against life objectives), affective (hedonic, happinessseeking), and eudaimonic (meaning-based).

Cognitive dimensions are usually measured by asking people to assess their overall satisfaction with life and are often measured on an annual basis, aggregated to national levels, e.g., the World Happiness Report or the Annual Population Survey of the UK Office of National Statistics, to complement economic assessments. Affective dimensions are measured by asking people to describe their emotions at a point in time and a eudemonic aspect captures the value and worthiness of the activities in which the person is involved (Kahneman and Riis 2005, Dolan and Metcalf 2012). Cognitive and affective responses in surveys represent independent but interrelated characteristics. A person with high levels of life satisfaction may be more predisposed to interpret everyday life experiences in a positive way, and a person who is currently experiencing positive emotion may report a higher life satisfaction (Kahneman and Riis 2005). Thus, whereas cognitive measures are more stable than affective measures (Diener et al. 2013), they do vary over short timescales (Kahnman and Krueger 2006).

Likewise, while material well-being and subjective well-being are correlated, the former does not directly influence the latter (Camfield et al. 2010, Diener and Tay 2015). The debates surrounding whether national happiness increases with economic growth are a testament to this (e.g., see Easterlin et al. 2010). Measured at the national level, Easterlin argues that economic growth and subjective well-being are not correlated over the long term, but that over the short-term economic downturns correlate with lower levels of subjective well-being (Easterlin 2015). The lack of consistency between economic and subjective well-being can be explained by the importance of the wider human experience, beyond material conditions. In both high- and lowincome settings, nonmaterial factors are crucial for human happiness (e.g., Narayan et al. 2000, Gough and McGregor 2007). There are three broad approaches for understanding how to generate the conditions necessary for this good life: welfare, capabilities, and psychological (Hojman and Miranda 2018).

Approaches that draw from economic ideas of happiness as welfare or utility, analyze subjective well-being from the perspective of the relative value of different physical and social needs being met. These approaches tend to identify objective life domains, e.g., health, income, relationships, that contribute to subjective well-being, and assess their relative importance, and differences among individuals and groups in the importance of different domains (e.g., Gough and McGregor 2007, Camfield and Esposito 2014, McGregor et al. 2015). Other approaches build on Sen's (2001) capabilities approach and conceptualize human well-being as the ability to take part in society in a meaningful way. Here subjective well-being results from personal freedoms, human agency, self-efficacy, dignity, and relatedness to others (e.g., Nussbaum 2001, Hojman and Miranda 2018, Markussen et al. 2018). Finally, psychological perspectives focus on individual differences in experiences of subjective well-being based on personality traits, inherited predisposition, and previous experiences (e.g., Diener et al. 2003). Recent advances have shown the positive material consequences of high life satisfaction (Diener et al. 2017).

Subjective well-being forms part of a broader suite of characteristics used to measure development progress, along with others such as social cohesion, inequality, procedural justice, security, and health. These new metrics move focus from material well-being and the dominance of assets, income, and expenditure as metrics of well-being to nonmaterial contributors (McGregor et al. 2015). Further, knowledge of drivers of subjective well-being can be used to identify potential target populations and priorities for development interventions (Diener et al. 2017) and can be used as an indicator to monitor progress on implementation of policies (e.g., Dolan and Metcalf 2012). However, people can report high levels of life satisfaction despite low levels of material 
well-being because of a process of adaptive preference formation (Sen 2001). Thus, marginalized groups can accept their quality of life such that conditions are normalized in the eyes of policy makers. If this is the case, then measuring subjective well-being for policy objectives could run counter to the best interests of the poor, as their utility will always be high (Qizilbash 2006, Clark 2012). Similarly, life satisfaction tends to return to original levels after any positive or negative change in circumstances, in a process known as the hedonic treadmill or set point theory (Jebb et al. 2018), although there are exceptions such as divorce and unemployment where dissatisfaction persists over time (Mancini et al. 2011). Such a mismatch between material and subjective indicators of well-being can also point to the multidimensional nature of well-being, and that people prioritize life domains beyond material factors (e.g., Camfield et al. 2010, McGregor et al. 2015).

When discussing the well-being of rural populations, and particularly those dependent on natural resources for their income, multidimensional well-being is constructed in the context of the environment and its changes (Schreckenberg et al. 2018). The ebb and flow of natural resources with seasonal changes in the climate could affect subjective well-being through various mechanisms. Connectedness to nature is known to have a wide range of health and well-being benefits (Nisbet et al. 2011) thus periods of proximity to the land and nature alternated with periods of off-farm livelihoods may influence well-being. Favorable climates have been linked to higher levels of subjective well-being (Kämpfer and Mutz 2013) so subjective well-being may change with the dry and rainy periods that drive the agricultural seasons. Food security is low during the agricultural low seasons, both because of a loss of income, and a low availability of subsistence produce to consume, with consequences for nutrition and health and implications for life satisfaction (e.g., Sibhatu and Qaim 2017). Unemployment is a strong correlate of low life satisfaction (Paul and Moser 2009). If main income earners are unable to secure alternative livelihoods during the agricultural low season, low satisfaction could result. The corollary of this, is that being actively involved in agricultural activities could engender feelings of autonomy, competence, and relatedness, associated with subjective well-being (Markussen et al. 2018). Finally, if harvests were not as successful as on other farms in the area, or not as successful or as lucrative as in previous years, then the relative differences may drive low life satisfaction (e.g., Asadullah and Chaudhury 2012).

Where it has been measured over time, subjective well-being has generally been measured as the emotional changes throughout the day (Kahneman et al. 2004, Hektner et al. 2007) or as changes in life satisfaction over the life course (e.g., Aglim et al. 2015). For example, Anglim et al (2015) looked at stability in subjective wellbeing measured annually over periods of 5 to 10 years. They found that people's scores were fairly stable, supporting the idea that people's satisfaction tends to return to a pre-existing level. They also found that there were meaningful differences between people in how much their life satisfaction fluctuates (Anglim et al. 2015). A u-shaped curve in satisfaction with the life course is observed in high income, English-speaking countries where satisfaction is lowest around 50 but this relationship does not hold for other countries, where satisfaction remains the same throughout the life course or continues to decrease with age (Anglim et al. 2015). Changes in positive and negative emotions are measured usual throughout one day and are explained by various factors such as the location and nature of the activity taking place (e.g., Schwanen and Wang 2014). Such techniques are well established in highincome settings and have been used to show, for example, the importance of the natural environment in generating positive affect (MacKerron and Mourato 2013) and to determine factors affecting satisfaction in the work place (Bryson and MacKerron 2017). Thus, there is need for a meso-level investigation into changes in subjective well-being intra-annually and a meaningful investigation into how established changes in livelihood activities and income interact with subjective well-being.

\section{METHODOLOGY}

\section{Survey design}

The data used in the present study were collected over the course of one year (December 2015-November 2016) in two upazilas (subdistricts) in Rangpur division in northwestern Bangladesh (see Fig. 1), a comparatively poor part of the country where rice production across Bangladesh's three rice seasons (the early monsoonal "Aus," rainy season "Aman," and irrigated dry season "Boro") predominates as a livelihood. We use data from a larger project with the overarching purpose of examining the importance of survey frequency (weekly, monthly, seasonally) in shaping recall and measurement error, across a wide range of common household survey tasks. Over the course of the study period, participants responded to questions on a number of topics that would typically be covered in large, integrated household surveys (e.g., Adams et al. 2016), such as agricultural production, food and nonfood consumption expenditures, income, and savings. A total of 46 different tasks were sent to participants, including a task on subjective well-being. Rather than addressing all the survey modules in a single sitting, however, the survey was dissected into short survey tasks to which participants would respond over the course of the study period. Importantly, the goal of the overarching project was to examine measurement error and recall bias, and in this design, the frequency with which respondents received these survey tasks was randomized, weekly, monthly (every 30 days), or seasonally (every 120 days), at the level of the task. Thus, each respondent would receive some tasks weekly, some monthly, and some only once per season. Randomization was uniform across all frequencies applicable to the task; not all tasks were asked at all frequencies, with the complete list of tasks and frequencies summarized in Bell et al. (2016, 2019).

The data were collected using a customized interface for Open Data Kit (ODK; Brunette et al. 2013) on Android smartphones, allowing the research team to interact with participants on a high frequency basis, with participants' continued engagement in data collection efforts incentivized by a "microtask for micropayment" mechanism. These varied in difficulty, typically requiring from 3 to 10 minutes to complete. Tasks were assigned a value ranging from one to five points, indicating the reward for completion, with a value of one corresponding to $10 \mathrm{MB}$ of data and five Bangladeshi taka (Bangladeshi currency, US\$1 = 84 BDT) of talk time, and five corresponding to $50 \mathrm{MB}$ of data and 25 taka (US\$0.3) of talk time. 
Fig. 1. Map showing the location of the field site. Upazilas = subdistricts.

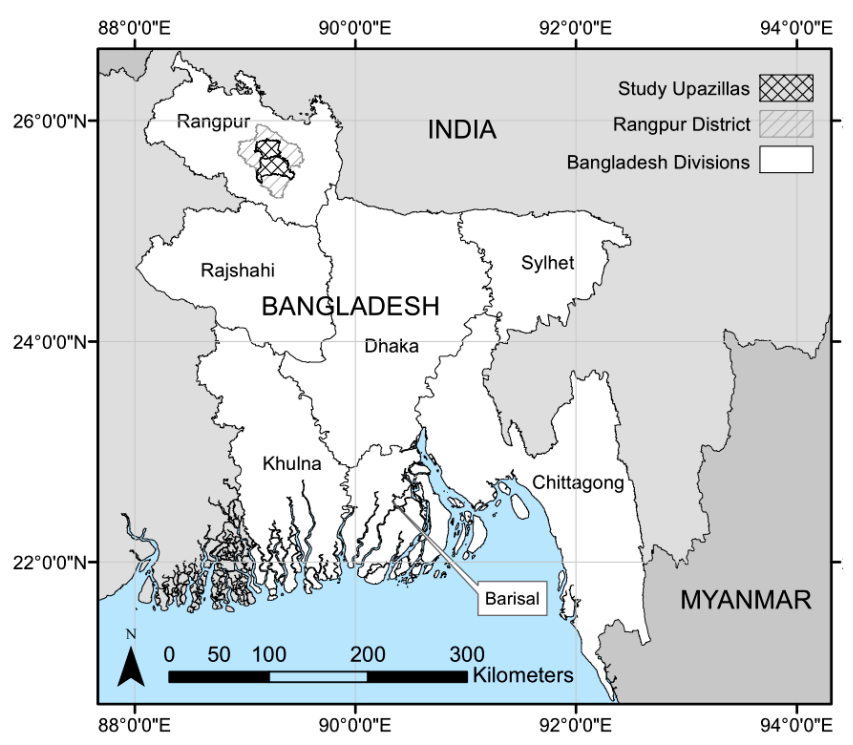

The sample was quasi-purposive in design, meant to capture potential early smartphone adopters (as a best guess of those who would be well-suited to responding over a long period to an unsupervised, smartphone-based survey). The two upazilas (subdistrict) that were selected (Mithapukur and Rangpur Sadar) had the highest literacy rates in Rangpur district in the 2011 Bangladesh census (Bangladesh Bureau of Statistics 2012). We randomly selected 40 villages from a pooled list of all villages in the two upazilas, and for each selected village, we solicited a short list of 25 potential participants from the local agricultural extension officer. The extension officer was asked to recommend farmers with whom they had contact, who were known to have or use mobile phones, and who might be inclined to use a smartphone. From this list of 25 names provided, we randomly selected 12 participants for our study (for a total of 480 participants across the 40 villages).

By soliciting a larger number of names directly and then randomly selecting a subset, we hoped to better capture aptitude for smartphones than would be possible in a random survey but avoid any issues of patronage that could arise through direct solicitation of names. Selected participants in all villages attended a full-day training event to sensitize them to the use of the smartphone, the use of ODK, the structure of our pilot (e.g., that they would receive payments for completing survey tasks), and to enable them to practice completing several different tasks. The average age of respondents was 33 (SD 11) and the average size of a household was 4.3 (SD 1.7); $55 \%$ of respondents were male, $61 \%$ were married. Levels of education were high: $30 \%$ of respondents had some form of higher education; $53 \%$ had attended school. These characteristics mark our sample as younger and more educated than a representative sample of household heads for the same region might be (Bell et al. 2016, 2019) but still, as we indicate above, highly reliant on agricultural income. Thus, we consider our sample appropriate (but not representative) to examine intraannual effects of agricultural labor and income on subjective wellbeing. See Bell et al. (2016) for more details on the survey process.

\section{Measuring subjective well-being}

Life satisfaction was measured using the Cantril self-anchoring scale (Cantril 1965), also used in the Gallop world polls and, as such, the World Happiness Report. The participants were asked to imagine a ladder with 10 steps, with the top of the ladder representing their best possible life and the bottom of the ladder representing their worst possible life. They were then asked to identify the ladder step on which they felt they stood at that point in time (as a number from 0 to 10). The order of the questions in this set was randomized both across individuals as well as across time. As with all tasks in this project, the frequency with which participants were given this task varied, with some participants receiving this task once per season (once every 120 days), some receiving this task once per month (once every 30 days), and some receiving this task every week.

\section{The field area}

The field area, Rangpur, is in the northwestern region of Bangladesh. People of this region, in general, belong to lower socioeconomic groups. According to National Population Census 2011, half of the population of Rangpur is illiterate $(47.2 \%)$, which is one of the lowest literacy rates among all divisions of Bangladesh (Sylhet having the lowest literacy rate at 45\%). Rural households in Rangpur are often affected by Monga (a Bengali term indicating seasonal hunger) and, as such, face cyclical forms of seasonal food insecurity. Monga mostly affects households from September to November. This can result in low employment, subsistence wages and, accordingly, low income (Khandker 2012, Bryan et al. 2014). Moreover, this region is often exposed to weather extremes such as droughts and floods. Northern Rangpur experienced severe droughts during 1994, 2000, and 2006. These droughts were associated with an increase in out-migration, decreases in agricultural production, loss of livestock, a rise in fish mortality, and an overall reduction in biodiversity (Islam et al. 2014).

Household incomes in our sample originate largely from agriculture ( $\sim 65 \%$ of household income, on average), with other significant sources including livestock $(\sim 10 \%)$ and wage labor $(\sim 10 \%)$. A principal components analysis across measured sources of income (agriculture, aquaculture, wages, livestock, remittances, and loans) revealed $96 \%$ of variance in income to be explained by the first principal component, indicating a lack of variation in income profile across the sample; that is to say, our sample is largely uniformly dependent on agricultural income, which in turn derives largely from rice, potatoes, and green vegetables.

\section{Data analysis}

Our analysis included identification of clusters of respondents using the K-means algorithm (Ding and He 2004) as implemented in Matlab, applied to the means and variances in responses to satisfaction items, for a total of two data points/dimensions per respondent. After identifying groups of respondents using Kmeans, we then developed predictive models of reported satisfaction over time, for the overall sample and for each group, by constructing regular time series variables in the following manner: for each variable of interest, a time series of 48 weekly 
Fig. 2. Upper panel shows average reported satisfaction with life from respondents selected to respond weekly to subjective well-being $(\mathrm{SWB})$ task $(\mathrm{n}=264$ initially; $\mathrm{n}=118$ continued respondents after week 40$)$. Lower panel shows average person-hours per household invested in agricultural labor from respondents selected to respond weekly to labor task $(n=129$ initially; $n=15$ continued respondents after week 40$)$.
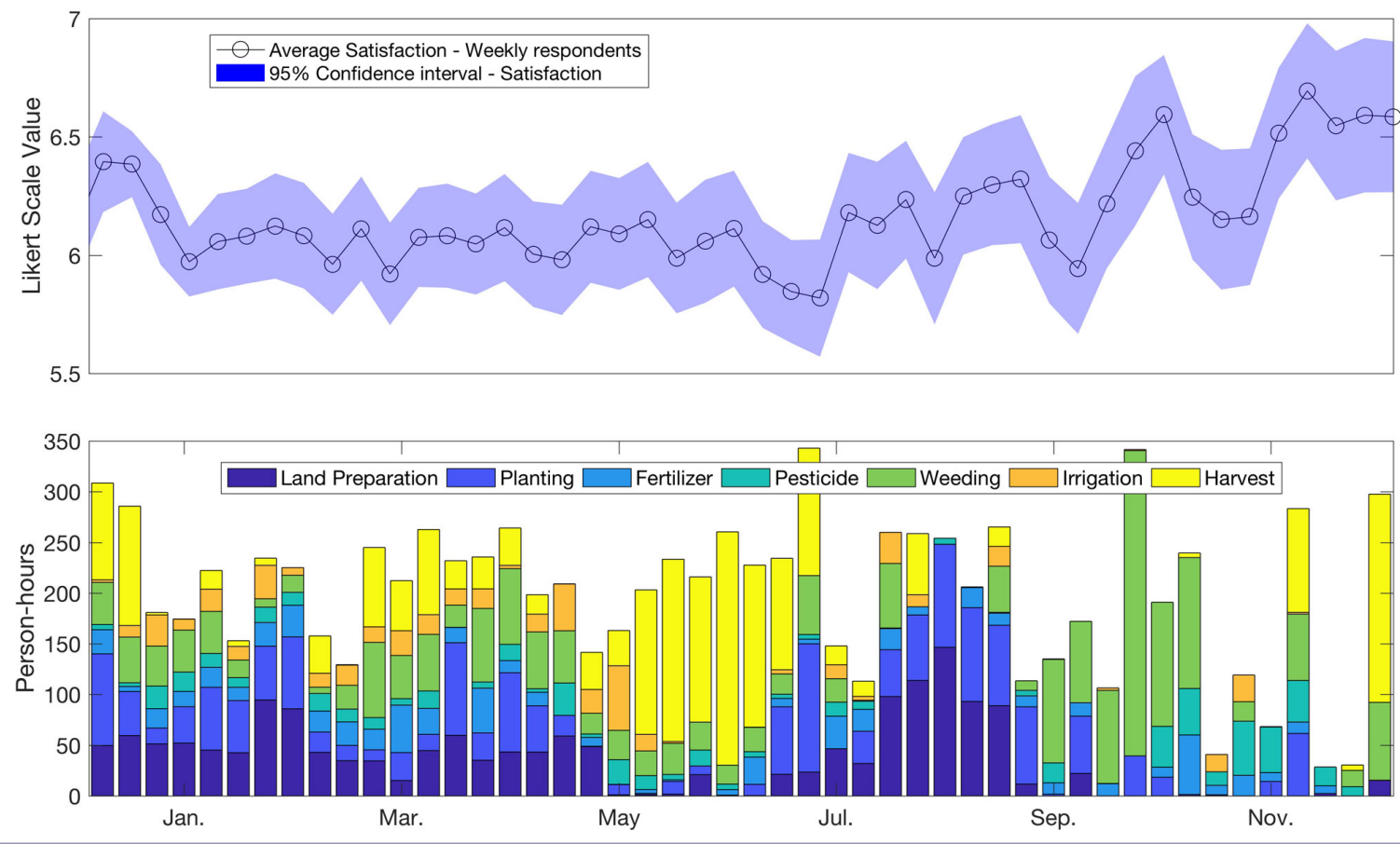

data points were initialized with non-numeric missing values. Our overarching experimental design meant that respondents were given different tasks at different frequencies, thus we needed a mechanism to put all responses on a common footing. Rather than discard the additional variation available at weekly resolution, we chose to impute weekly reported values from tasks that were asked with monthly or seasonal frequency. Responses from respondents who completed the task weekly were placed directly in the appropriate week, while those who reported cumulative responses over 30 or 120 days had those values spread across the preceding 4 and 17 weeks, respectively, e.g., a reporting of 100 hours of labor over the previous 30 days was treated as 25 hours per week over the 4 weeks prior to the response. Second, a correction factor was applied to account for differences in recall across different frequencies, which we have identified in a separate analysis as being significant for most labor and consumption variables (Bell et al. 2019). Specifically, we rescaled all weekly and seasonal responses in order that the between-subject means for each variable measured equaled those for the between-subject means of monthly responses, arbitrarily chosen as a baseline. This method allows for lower frequency responses to be used, albeit with lower resolution. The cost to our analysis of this lower resolution data is that some significant effects of time-variant factors may be missed.

We modeled satisfaction as a function of both (relatively) time invariant variables (e.g., demographic factors and material wealth) and variables that change throughout the year (the agricultural cycle), using Newey-West standard errors with a lag of, at most, three time periods (weeks). Material well-being was measured through fixed assets (latrine type and number of rooms in house), income (taka per week), and expenditure (represented through the proxy of meat consumption in $\mathrm{kg}$ per week). Sociodemographic factors were included through the variables: age, years of education, marital status, gender. We also controlled for the administrative district in which the individual lives. We represented the agricultural calendar through variables representing the different activities with which household labor is engaged: land preparation, planting, fertilizers, pesticides, weeding, irrigation, and harvesting. In our sample, common crops included the Aman rice crop (sown in July/August and harvested in November/December) and the Aus rice crop (sown in March/ April and harvested in June/July); less common was the irrigated dry-season Boro rice crop (sown in December/January and harvested in April/May). Finally, we incorporated a variable representing the presence or absence of household income shocks, such as the death or illness of a main income earner.

\section{Caveats}

The subjective well-being tasks were contextualized with questions about location, activity, and company. However, most respondents waited until they were at home to complete the survey tasks, and as such the setting was overwhelmingly at home with family and could not help to explain differences in subjective wellbeing. Similarly, although we measured positive and negative affect, the question was phrased as "over the past 24 hours" and as such in this analysis we considered the evaluative dimension of the task to be too high to use as an affect measure in comparison to reported life satisfaction (RLS); preferable would have been to 
ask questions on a range of emotions, in line with Csikszentmihalyi and Larson's (2014) experience sampling method. However, with some modifications, in particular, a time limit on answering the question, the technology used in this study could be used to collect momentary measures of well-being.

Finally, the survey was designed predominantly to collect agricultural data. Thus, we recognize that the range of predictor variables included in the model is not representative of the state of knowledge on the contributors to subjective well-being across multiple life domains in low-income, rural settings. For example, it would have been desirable to have collected information on inequality, feelings of self-efficacy, quality of family life and personality factors.

\section{RESULTS}

Patterns in weekly variation in satisfaction with life

Figure 2a shows average weekly RLS scores for the whole sample over the year. Figure $2 b$ maps these scores against the agricultural calendar, constructed using the household person-hours spent on different agricultural activities that week. In general, people are satisfied, with average values ranging from between five and seven out of ten. The data show a general increase in RLS towards the end of the period but also an increase in variation. The plot shows that RLS varies considerably from week-to-week, thus, we investigate RLS as a distribution over time.

\section{K-means clustering of groups based on satisfaction as a distribution}

Using this distribution of reported life satisfaction, we can cluster our respondents using normalized variables of mean (on average how satisfied people are) and standard deviation (how stable that satisfaction is) using the k-means clustering algorithm, that assigns data to one of a user-input number of categories based on minimizing Euclidean distance. We explored clustering into two to six different categories, finding reasonably distinct response categories with $n=4$ (see Silhouette values in Fig. 3; a well-defined cluster will have Silhouette values greater than 0.5 for most of its points) that we label "Satisfied," "Dissatisfied," "Indifferent," and "Ambivalent" for the case of four clusters in kmeans (RLS-Over-Time groups; see Fig. 3). The Satisfied group are those with consistently high levels of satisfaction; the Dissatisfied group those with consistently low satisfaction; the Ambivalent group shows scores that fluctuate throughout the year; and the Indifferent report consistently midlevel scores.

Predicting group membership using socio-demographic factors We ran probit regressions to predict membership in each of the RLS-Over-Time groups based only on the time-invariant (or at least slow changing), socio-demographic factors (Table 1). Material wealth significantly predicted Satisfaction: this group was more likely to have a flush toilet and more rooms in their house. All other groups were less likely to have these assets. There were also geographical factors that differentiated the Satisfied group from all the others because it was the only group less likely to be from the control region of Mithapukur. The Satisfied group can be characterized as more likely to be younger, less educated, unmarried women, with assets.
Fig. 3. K-means clustering of individuals based on magnitude and standard deviation of reported life satisfaction. Silhouette values greater than 0.5 are indicative of a point fitting within the cluster to which it is allocated better than to any other clusters.
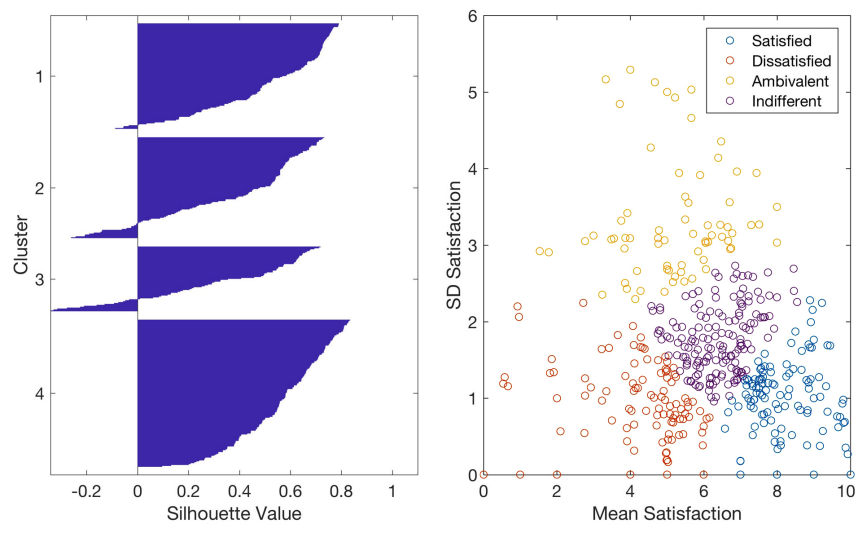

Table 1. Coefficients for probit models predicting membership of each of the satisfaction groups (against baseline of membership in any other group). Coefficients give the change in likelihood of belonging to a group (in z-scores, or standard deviations away from the mean) from a unit change in the predictor; for example, a one-year increase in age shifts the z-score down by 0.0026 . The dissatisfied group is all male. ${ }^{* *} \mathrm{p}<0.01,{ }^{* *} \mathrm{p}<0.05,{ }^{*} \mathrm{p}<0.1$

\begin{tabular}{lcccc}
\hline \hline & Indifferent & Satisfied & Ambivalent & Dissatisfied \\
\hline Age & $-0.00262^{* * *}$ & $-0.00227^{* * *}$ & $0.00366^{* * *}$ & -0.00121 \\
Years of education & $0.0374^{* * *}$ & $-0.0110^{* * *}$ & $-0.0544^{* * *}$ & $0.0362^{* * *}$ \\
Married (1 - yes) & $0.145^{* * *}$ & $-0.334^{* * *}$ & $0.260^{* * *}$ & $-0.133^{* *}$ \\
Gender (1 - male) & $0.502^{* * *}$ & $-0.456^{* * *}$ & $-0.189^{* * *}$ & \\
Has flush toilet & $-0.103^{* * *}$ & $0.366^{* * *}$ & $-0.318^{* * *}$ & $-0.350^{* * *}$ \\
No. of rooms in house & $-0.0402^{* * *}$ & $0.105^{* * *}$ & $-0.139^{* * *}$ & -0.00147 \\
Upazilla Control (1 - & $0.135^{* * *}$ & $-0.499^{* * *}$ & $0.412^{* * *}$ & $0.357^{* * *}$ \\
Mithapukur) & & & & \\
Constant & $-0.944^{* * *}$ & $0.148^{* *}$ & $-0.137 *$ & $-1.955^{* * *}$ \\
Observations & 9888 & 9888 & 9888 & 8832 \\
\hline
\end{tabular}

Members of the Indifferent group were younger, more educated, married men, with fewer assets. The Ambivalent group were more likely to be older, less educated, married women with fewer assets. The Dissatisfied group consisted entirely of men, and membership was predicted by increased education, single status, and fewer assets. In the following section we predict RLS for the entire sample and these groups in order to see if characteristics of RLS, that is to say the level and stability of life satisfaction and showing RLS as a distribution, influenced the objective predictors of RLS.

\section{Predicting reported life satisfaction}

We apply a time-series regression analysis using Newey-West standard errors in order to model RLS for the whole sample and for the RLS-Over-Time groups. Specifically, we predict RLS using three sets of variables: (i) time-invariant socio-demographic 
Table 2. Summary statistics showing characteristics of different RLS-Over-Time groups. Numbers for agricultural activities represent person-hours per week of household labor spent in this activity. Scale for reporting shocks: 0 - none; 1 - low impact; 2 - medium impact; 3 - high impact.

\begin{tabular}{|c|c|c|c|c|c|}
\hline & $\begin{array}{c}\text { All } \\
(n=353)\end{array}$ & $\begin{array}{l}\text { Satisfied } \\
(\mathrm{n}=120)\end{array}$ & $\begin{array}{c}\text { Dissatisfied } \\
(\mathrm{n}=145)\end{array}$ & $\begin{array}{c}\text { Ambivalent } \\
(n=66)\end{array}$ & $\begin{array}{l}\text { Indifferent } \\
(\mathrm{n}=22)\end{array}$ \\
\hline Age & 35.17 & 32.87 & 32.62 & 67.11 & 32.34 \\
\hline Years of education & 8.68 & 8.02 & 9.14 & 8.84 & 8.56 \\
\hline Marital status & $32 \%$ & $28 \%$ & $33 \%$ & $47 \%$ & $31 \%$ \\
\hline Gender ( $\%$ male $)$ & $91 \%$ & $86 \%$ & $94 \%$ & $90 \%$ & $91 \%$ \\
\hline \# Rooms in house & 3.94 & 4.32 & 3.87 & 3.84 & 3.64 \\
\hline Has flush latrine & 0.32 & 0.39 & 0.30 & 0.21 & 0.31 \\
\hline Household meat consumption & 0.09 & 0.05 & 0.05 & 0.07 & 0.21 \\
\hline Household income taka/week & 3501.69 & 2107 & 2637 & 1849 & 7384 \\
\hline Land preparation & 13.77 & 28.39 & 8.77 & 16.48 & 4.94 \\
\hline Planting & 11.87 & 24.64 & 4.01 & 6.97 & 13.26 \\
\hline Fertilizers & 19.79 & 22.77 & 21.20 & 4.82 & 18.32 \\
\hline Pesticides & 2.48 & 0.93 & 2.45 & 4.51 & 3.73 \\
\hline Weeding & 18.18 & 19.79 & 18.93 & 8.93 & 17.77 \\
\hline Irrigation & 2.37 & 0.58 & 1.47 & 6.06 & 5.08 \\
\hline Harvesting & 3.42 & 1.39 & 6.27 & 1.43 & 1.00 \\
\hline Most severe shock experienced this period & 0.03 & 0.03 & 0.03 & 0.03 & 0.04 \\
\hline
\end{tabular}

characteristics; (ii) a selection of agricultural labor, consumption, and event-experience variables for the current period, and (iii) two-week lagged periods.

Current period variables represent the situation experienced by that individual when they answered the question, and include weekly income in taka and meat consumption (as a crude proxy for expenditure), the presence of income shocks, and the agricultural activities on which the household is expending labor at that point in time. The 2-week lagged variables are included to take into account that the benefits or disadvantages of agricultural activity may not be realized until a period after the event, for example, selling of products after processing, lower income after paying workers, or debt resulting from income shocks. Time invariant variables control for the sociodemographic characteristics of the individual. Table 2 provides summary statistics on these variables for the whole sample and each of the RLS/Time groups.

Overall, the fraction of variance explained by our model is not overly high, around $10 \%$ for all models except the Indifferent group, for which the number of data points is rather low. However, we caution that maximizing explained variance is not always (and is not here) a central goal. Recognizing that RLS is shaped by an innumerable number of different factors, we built a model that included our best representation of time-invariant and timevariant factors specific to a rural lifestyle in Rangpur, Bangladesh. Thus, our interpretation of model fit here is to note that somewhere on the order of $10 \%$ of variation in RLS appears to be explained by our best representation of rural agricultural life.

For the whole sample, increased age, more years of education, being married and a man reduce the likelihood of being satisfied (Table 3). Material well-being in the form of assets and expenditure (meat consumption) increase the likelihood of being satisfied. Thus, RLS is predicted by objective measures of wellbeing. However, income and income shocks are not significant predictors of reported life satisfaction at the group level.
With respect to the agricultural cycle, land preparation and harvesting activities are associated with higher satisfaction in the current period and planting and fertilizer application are associated with higher satisfaction with a two-week time lag. Planting, weeding, and irrigation activities are associated with less satisfaction in the current period, and land preparation, pesticide application, weeding, irrigation, and harvest activities are associated with less satisfaction after a two-week time lag.

The material predictors of life satisfaction change when the sample is disaggregated by RLS-Over-Time group and the direction of the relationship can vary between groups. For example, income becomes a significant predictor when the sample is disaggregated, but the relationship is positive in the Dissatisfied and Ambivalent groups, but negative in the Satisfied group. For the whole sample, number of rooms in the house (as a proxy for asset-based wealth) has a positive relationship with RLS for the whole sample, but when disaggregated the Satisfied group shows a negative relationship between assets and RLS.

Furthermore, the relationship between some agricultural activities and RLS becomes significant or insignificant, and the direction of the relationship can change. For example, in the Ambivalent group, if agricultural activities are significantly associated with RLS, the relationship is positive. However, in the Satisfied group, fewer agricultural activities are significantly associated with RLS than in the other groups, and the one significant relationship is negative (weeding). However, there are not always differences between the whole sample and disaggregated groups. Land preparation as a lagged variable is negatively associated with RLS for the whole sample, and all disaggregated groups.

\section{DISCUSSION}

This is the first study of its kind to measure life satisfaction on high temporal timescales in a low income, rural setting. In low income settings, subjective well-being is usually measured through questions incorporated into annual, or occasionally seasonal, 
Table 3. Results of the regression model predicting reported life satisfaction based on socio-demographics, wealth level, and agricultural activity for the whole sample, and disaggregated by satisfaction groups. For shocks: 0 - none; 1 - low impact; 2 - medium impact; 3 high impact. $* * * p<0.01, * * \mathrm{p}<0.05,{ }^{*} \mathrm{p}<0.1$

\begin{tabular}{|c|c|c|c|c|c|}
\hline & All groups & Satisfied & Dissatisfied & Ambivalent & Indifferent \\
\hline $\begin{array}{l}\text { Socio-demographic predictors of group } \\
\text { membership }\end{array}$ & & $\begin{array}{c}\text { Younger, less } \\
\text { educated, } \\
\text { unmarried women } \\
\text { with assets }\end{array}$ & $\begin{array}{l}\text { Better educated, } \\
\text { single men with } \\
\text { fewer assets }\end{array}$ & $\begin{array}{l}\text { Older, less } \\
\text { educated, married } \\
\text { women with fewer } \\
\text { assets }\end{array}$ & $\begin{array}{c}\text { Younger, better } \\
\text { educated, married } \\
\text { men with fewer } \\
\text { assets }\end{array}$ \\
\hline \multicolumn{6}{|l|}{ Current period variables } \\
\hline Meat consumption (kg/week) & $0.00609 * * *$ & -0.000205 & -0.000945 & -0.156 & 0.0584 \\
\hline Income (taka/week) & $1.47 \mathrm{e}-06$ & $-4.99 \mathrm{e}-06^{* * *}$ & $5.96 \mathrm{e}-06 * * *$ & $2.04 \mathrm{e}-06 * * *$ & $-3.99 \mathrm{e}-05$ \\
\hline Land preparation (hours/week) & $0.000258^{*}$ & 0.000439 & $0.000678^{*}$ & 0.0515 & -0.0103 \\
\hline Planting (hours/week) & $-0.000501 * *$ & 0.000376 & -0.00217 & $0.00385 * *$ & 0.0183 \\
\hline Fertilizer (hours/week) & $-3.17 \mathrm{e}-05$ & $-8.69 e-06$ & $-0.000194 * * *$ & $0.000620 * * *$ & $-0.00563^{* *}$ \\
\hline Pesticide (hours/week) & 0.000862 & -0.000195 & $0.00295 * * *$ & -0.101 & $-0.621 * * *$ \\
\hline Weeding (hours/week) & $-4.76 \mathrm{e}-05^{* * *}$ & $-3.72 \mathrm{e}-05 * * *$ & 0.000124 & $0.000272 * * *$ & $0.000433 * *$ \\
\hline Irrigation (hours/week) & $-0.000986^{* * *}$ & 0.00362 & $-0.00577 * * *$ & & $0.00632 * * *$ \\
\hline Harvest (hours/week) & $0.000818^{* *}$ & -0.00138 & $0.000538 * * *$ & 0.00150 & $0.0486 * * *$ \\
\hline Most severe shock experienced this period & -0.167 & $-0.203 * *$ & -0.202 & $-0.720 *$ & 0.188 \\
\hline \multicolumn{6}{|l|}{ Two-week lagged variables } \\
\hline Meat consumption $(\mathrm{kg} /$ week $)$ & $0.0116^{* * *}$ & 0.211 & $0.00444 * * *$ & 0.110 & 0.122 \\
\hline Income (taka/week) & $9.71 \mathrm{e}-08$ & $-2.22 \mathrm{e}-06^{* *}$ & $-1.63 e-06$ & $-8.88 \mathrm{e}-08$ & $3.97 \mathrm{e}-05$ \\
\hline Land preparation (hours/week) & $-0.000184 *$ & -0.000139 & $-0.000295^{* * *}$ & $-0.00190 * * *$ & 0.00600 \\
\hline Planting (hours/week) & $2.07 \mathrm{e}-05^{* * *}$ & $1.76 \mathrm{e}-05$ & $-8.38 \mathrm{e}-06$ & $0.00358 * *$ & -0.0103 \\
\hline Fertilizer (hours/week) & $5.69 \mathrm{e}-05^{* * *}$ & $4.37 \mathrm{e}-05 * * *$ & $-8.50 \mathrm{e}-06$ & $1.34 \mathrm{e}-06$ & $-0.00208 * * *$ \\
\hline Pesticide (hours/week) & $-0.000470 * *$ & -0.000855 & 0.000580 & $-0.000547 * * *$ & 0.000566 \\
\hline Weeding (hours/week) & $-3.78 \mathrm{e}-05^{* * *}$ & $-2.27 \mathrm{e}-05 * * *$ & $-9.60 \mathrm{e}-05^{* *}$ & $0.000184 * * *$ & $9.72 \mathrm{e}-05$ \\
\hline Irrigation (hours/week) & -0.000586 & $0.00128 * * *$ & -0.000645 & $-0.00126 * * *$ & -0.000159 \\
\hline Harvest (hours/week) & $-0.000138 * * *$ & $-3.68 \mathrm{e}-06$ & 0.00117 & -0.00328 & $0.0428 * *$ \\
\hline Most severe shock experienced this period & 0.0280 & -0.174 & 0.0381 & -0.00482 & $0.468 * * *$ \\
\hline \multicolumn{6}{|l|}{ Time-invariant } \\
\hline Age & $-0.00134 *$ & 0.00412 & 0.00131 & -0.00150 & $0.0889 * * *$ \\
\hline Years of education & $-0.0249 *$ & 0.0124 & $-0.0961 * * *$ & -0.00811 & $-0.265 * * *$ \\
\hline Married (1 - yes) & $-0.467 * * *$ & $0.348 * * *$ & $0.360 * *$ & -0.231 & -0.0432 \\
\hline Gender $(1$ - male $)$ & $-1.171 * * *$ & $-0.373 * *$ & $-0.377 * * *$ & -0.565 & \\
\hline Has a flush toilet & $0.254 * *$ & $-0.257 * * *$ & $0.255^{* *}$ & 0.367 & $1.544 * * *$ \\
\hline No. of rooms in house & $0.0826 * * *$ & $-0.138 * * *$ & $0.0299 * * *$ & 0.00770 & $0.238 * *$ \\
\hline Upazilla Control (1 - Mithapukur) & $-0.370 * * *$ & $0.320 * * *$ & $0.211^{*}$ & $-0.749 *$ & $0.903 * * *$ \\
\hline Constant & $7.268 * * *$ & $5.634 * * *$ & $8.400 * * *$ & $6.901 * * *$ & -0.363 \\
\hline Observations & 3,479 & 1,516 & 1,399 & 362 & 202 \\
\hline R-squared & 0.085 & 0.074 & 0.117 & 0.093 & 0.592 \\
\hline
\end{tabular}

household surveys (e.g., Adams et al. 2016) that tend to take place during the dry season when access is easier. This creates issues for generalization and comparability (Jolliffe and Serajuddin 2018) because across the agricultural calendar, a range of objective life domains, e.g., income security, sense of community, or relationships, could be affected sufficiently such that satisfaction scores fall (Chambers et al. 1981, Dercon and Krishnan 2000, Hulme and Shepard 2003).

Questions on life satisfaction ask a person to cognitively reflect on whether they are meeting their own objectives in life, with the individual deciding which dimensions to include in the assessment, e.g., income, relationships, health, or community, and how to weight them. Responses should be stable enough that they are not reflecting short-term fluctuations in emotions. However, the responses must also be sensitive enough to change with life conditions (Diener et al. 2013). Without temporal context we cannot tell from the one-off or annual social surveys, whether the response given that day reflects a cognitive assessment or the dominant emotions on that day. Further, we do not know if that person is predisposed to interpret life in a positive or negative way. This dataset allows us to contextualize one-off life satisfaction scores.

Our results reveal high levels of variability between individuals in their life satisfaction scores over time. However, using cluster analysis we identified four natural groups based on the levels and stability of life satisfaction over time (RLS-Over-Time groups): those with consistently high, low, medium scores, and those whose scores fluctuated highly from week to week. For three of the four groups, consisting of the majority of the population surveyed $(90 \%)$, evaluations of life satisfaction are generally stable yearround. Only one group surveyed (the Ambivalent group, representing $10 \%$ of the population) reports highly fluctuating life satisfaction scores. High variability between individuals, but general stability over time, is consistent with patterns of wellbeing when measured annually over the life course (Anglim et al. 2015).

Socio-demographic characteristics were significant predictors of membership of our RLS-Over-Time groups; for example, the 
Dissatisfied group were more likely to be educated, unmarried men. In these rural communities of Bangladesh, like elsewhere, age, sex, marital status, and levels of education determine an individual's status in society, opportunities, norms, and expectations upon them (Camfield et al. 2010). Although in general, people have been found to prioritize education for subjective well-being, i.e., well-being increases with education (Camfield et al. 2009), higher levels of education could be associated with dissatisfaction in our sample because of increased awareness of opportunities unattained. This is consistent with arguments for the importance of relative well-being (Coulthard et al. 2018) and well-being generated by position in society as well as individual personality traits and objective conditions (Helliwell 2003, Kahneman and Krueger 2006). Some results were surprising, such as the negative association between assets and life satisfaction in the Satisfied group. In this case, assets could be associated with higher levels of debt, for example, or increased responsibility within the community (Adams et al. 2018).

Our data show that life satisfaction is also sensitive to seasonal changes in agricultural activities. For example, land preparation and harvesting activities are associated with higher satisfaction in the current period and planting and fertilizer application are associated with higher satisfaction with a two-week time lag. Land preparation could be associated with life satisfaction because of optimism of a new season, high levels of communal activity; however, it is also a period where energy expenditure tends to exceed energy input, i.e., people are working hard but on low food supplies (Chambers et al. 1981). Harvesting is associated with life satisfaction, which is consistent with increases in income and food security. Planting, weeding, and irrigation activities were associated with less satisfaction in the current period, and land preparation, pesticide application, weeding, irrigation, and harvest activities were associated with less satisfaction after a twoweek time lag. These results could be interpreted as the negative impact of monotonous agricultural activities with little positive return. The effect sizes are not large but we would not expect them to be considering the range of influences on subjective well-being. Furthermore, in this research we worked with land-owing farmers, who were likely to have a higher technological literacy. Landowners, because of their larger asset base and higher levels of social capital, are able to smooth the effects of seasonality more successfully than the landless (Lazar et al. 2019).

Finally, the ability to examine RLS over time as a distribution (with a mean and variation) and not simply as a point estimate allows us to characterize respondents into groups whose RLS varied differently over time. Disaggregating the analysis by RLSOver-Time groups, the objective determinants of life satisfaction change. That is to say, the things that make someone who is generally satisfied, more satisfied, differ from the things that make someone who is generally dissatisfied, more satisfied and this was true for both agricultural and time-invariant factors. For example, in the Ambivalent group, where agricultural activities are significantly associated with life satisfaction, the relationship is positive. However, in the Satisfied group, fewer agricultural activities are significantly associated with life satisfaction than in the other groups, and the one significant relationship is negative (weeding).
Because membership of the life satisfaction groups is predicted by socio-demographic variables, it may be that these differences are a result of the different capabilities of the farmers with different positions in the rural community, for example, their ability to employ farm labor or hire machinery (Adams et al. 2018, Ballet et al. 2018). Also, gender might be playing a role, because different RLS-Over-Time groups were more likely to be associated with men or women. Women in Bangladesh are not heavily involved in agricultural labor in rice production (Rahman 2000) but where they are involved it tends to be as hired laborers when there is insufficient male labor (Sraboni et al. 2014). Alternatively, these results could be reflecting the role that subjective well-being can play in determining material well-being outcomes; in highincome settings happier people tend to be more successful in work (Diener et al. 2017). Or these results could be reflecting the role of positive emotions in psychological resilience and coping under difficult circumstances (Tugade et al. 2004).

\section{CONCLUSION}

Subjective well-being as a core element of multidimensional wellbeing, the important role of the natural environment in producing well-being, and the seasonality of rural livelihoods are wellestablished (e.g., Hoque et al. 2018 in Bangladesh). However, there has been very little work bringing these ideas together to reflect on the seasonality of subjective well-being and its implications in rapidly changing rural environments (Hoque et al. 2017). Here we show that the agricultural calendar and its highs and lows of activity and income are associated with reported life satisfaction in landowning farmers in Bangladesh, and not only through their impact on material wealth. We also show that the impact on life satisfaction of activities depends on the characteristics of that person's reported life satisfaction.

The results show that subjective well-being needs to be measured over time, as a sequence or shape rather than a point in time. The average level of life satisfaction and its stability has provided novel insights into the social, cultural, and economic determinants of life satisfaction and the sensitivity of that life satisfaction to changes in life conditions over the meso-temporal scale. Although a measure of subjective well-being cannot be taken as a measure of utility because of adaptive preference formation, it can help policy makers to understand the life dimensions that matter to people and shift focus from addressing material poverty only.

Responses to this article can be read online at: http://www.ecologyandsociety.org/issues/responses. php/11187

\section{Acknowledgments:}

This work derives from a project led by Andrew Bell, Patrick Ward, Md. Ehsanul Haque Tamal, and Mary Killilea; supported by the Cereal Systems Initiative for South Asia (CSISA) of the Consultative Group on International Agricultural Research (CGIAR), with generous funding provided by the United States Agency for International Development (USAID) and the Bill and Melinda Gates Foundation. We acknowledge funding from the UK 
Natural Environment Research Council, Economic and Social Research Council and Department for International Development in supporting Helen Adams's time on the project Assessing Health, Livelihoods, Ecosystem Services And Poverty Alleviation In Populous Deltas (ESPA Deltas; NERC Grant No. NE/J000892/1). Discussions with Barnaby Andrews (University of East Anglia) and the Contested Development research group at KCL were invaluable in shaping the manuscript.

\section{LITERATURE CITED}

Adams, H., W. N. Adger, S. Ahmad, A. Ahmed, D. Begum, A. N. Lázár, Z. Matthews, M. M. Rahman, and P. K. Streatfield. 2016. Spatial and temporal dynamics of multidimensional well-being, livelihoods and ecosystem services in coastal Bangladesh. Scientific Data 3:160094. https://doi.org/10.1038/sdata.2016.94

Adams, H., W. N. Adger, M. Ahmed, H. Huq, R. Rahman and M. Salehin. 2018. Defining social-ecological systems in southwest Bangladesh. Pages 405-424 in R. J. Nicholls, C. W. Hutton, W. N. Adger, S. E. Hanson, M. M. Rahman, and M. Salehin, editors. Ecosystem services for well-being in deltas. Palgrave Macmillan, Cham, Switzerland. https://doi.org/10.1007/978-3-319-71093-8 22

Adams, H., W. N. Adger, H. Huq, R. Rahman, and M. Salehin. 2013. Wellbeing-ecosystem service links: mechanisms and dynamics in the southwest coastal zone of Bangladesh. ESPA Deltas Working Paper 2. University of Southampton, Southampton, UK.

Anglim, J., M. K. Weinberg, and R. A. Cummins. 2015. Bayesian hierarchical modeling of the temporal dynamics of subjective well-being: a 10 year longitudinal analysis. Journal of Research in Personality 59:1-14. https://doi.org/10.1016/j.jrp.2015.08.003

Asadullah, M. N., and N. Chaudhury. 2012. Subjective well-being and relative poverty in rural Bangladesh. Journal of Economic Psychology 33(5):940-950. https://doi.org/10.1016/j.joep.2012.05.003

Ballet, J., L. Marchand, J. Pelenc, and R. Vos. 2018. Capabilities, identity, aspirations and ecosystem services: an integrated framework. Ecological Economics 147:21-28. https://doi. org/10.1016/j.ecolecon.2017.12.027

Bangladesh Bureau of Statistics. 2012. Bangladesh household income and expenditure survey 2010: key findings and results. Bangladesh Bureau of Statistics and World Bank, Dhaka, Bangladesh.

Baracchini, T., A. A. King, M. J. Bouma, X. Rodó, E. Bertuzzo, and M. Pascual. 2017. Seasonality in cholera dynamics: a rainfalldriven model explains the wide range of patterns in endemic areas. Advances in Water Resources 108:357-366. https://doi. org/10.1016/j.advwatres.2016.11.012

Basu, K., and M. Wong. 2015. Evaluating seasonal food storage and credit programs in east Indonesia. Journal of Development Economics 115:200-216. https://doi.org/10.1016/i.jdeveco.2015.02.001

Becquey, E., F. Delpeuch, A. M. Konaté, H. Delsol, M. Lange, M. Zoungrana, and Y. Martin-Prevel. 2012. Seasonality of the dietary dimension of household food security in urban Burkina Faso. British Journal of Nutrition 107(12):1860-1870. https://doi. org/10.1017/s0007114511005071
Bell, A., P. Ward, M. E. H. Tamal, and M. Killilea. 2019. Assessing recall bias and measurement error in high-frequency social data collection for human-environment research. Population and Environment 40(3):325-345. https://doi.org/10.1007/s11111-019-0314-1

Bell, A. R., P. S. Ward, M. E. Killilea, and M. E. H. Tamal. 2016. Real-time social data collection in rural Bangladesh via a 'microtasks for micropayments' platform on android smartphones. PLoS ONE 11(11):e0165924. https://doi. org/10.1371/journal.pone.0165924

Brunette, W., M. Sundt, N. Dell, R. Chaudhri, N. Breit, and G. Borriello. 2013. Open data kit 2.0: expanding and refining information services for developing regions. Proceedings of the 14th Workshop on Mobile Computing Systems and Applications. Association for Computing Machinery, New York, New York, USA. https://doi.org/10.1145/2444776.2444790

Bryan, G., S. Chowdhury, and A. M. Mobarak. 2014. Underinvestment in a profitable technology: the case of seasonal migration in Bangladesh. Econometrica 82(5):1671-1748. https:// doi.org/10.3982/ECTA10489

Bryson, A., and G. MacKerron. 2017. Are you happy while you work? Economic Journal 127(599):106-125. https://doi.org/10.1111/ ecoj.12269

Camfield, L., K. Choudhury, and J. Devine. 2009. Well-being, happiness and why relationships matter: evidence from Bangladesh. Journal of Happiness Studies 10(1):71-91. https://doi. org/10.1007/s10902-007-9062-5

Camfield, L., and L. Esposito. 2014. A cross-country analysis of perceived economic status and life satisfaction in high-and lowincome countries. World Development 59:212-223. https://doi. org/10.1016/j.worlddev.2014.01.018

Camfield, L., M. Guillen-Royo, and J. Velazco. 2010. Does needs satisfaction matter for psychological and subjective wellbeing in developing countries: a mixed-methods illustration from Bangladesh and Thailand. Journal of Happiness Studies 11 (4):497-516. https://doi.org/10.1007/s10902-009-9154-5

Cantril, H. 1965. The pattern of human concerns. Rutgers University Press, New Brunswick, New Jersey, USA.

Chambers, R., R. Longhurst, and A. Pacey. 1981. Seasonal dimensions to rural poverty. Frances Pinter, London, UK.

Chowdhury, A. M. R., A. Bhuiya, M. E. Chowdhury, S. Rasheed, Z. Hussain, and L. C. Chen. 2013. The Bangladesh paradox: exceptional health achievement despite economic poverty. The Lancet 382(9906):1734-1745. https://doi.org/10.1016/S0140-6736 (13)62148-0

Clark, D. A. 2012. Adaptation, poverty and development: the dynamics of subjective well-being. Palgrave Macmillan, London, UK.

Copestake, J., M. Guillen-Royo, W. J. Chou, T. Hinks, and J. Velazco. 2009. The relationship between economic and subjective wellbeing indicators in Peru. Applied Research in Quality of Life 4(2):155-177. https://doi.org/10.1007/s11482-009-9070-1

Coulthard, S., J. A. McGregor, and C. White. 2018. Multiple dimensions of wellbeing in practice. Pages 243-256 in $\mathrm{K}$. 
Schreckenberg, G. Mace, and M. Poudyal, editors. Ecosystem services and poverty alleviation: trade-offs and governance. Routledge, Oxford, UK.

Csikszentmihalyi, M., and R. Larson. 2014. Validity and reliability of the experience-sampling method. Pages 35-54 in M. Csikszentmihalyi, editor. Flow and the foundations of positive psychology. Springer, Dordrecht, The Netherlands. https://doi. org/10.1007/978-94-017-9088-8 3

Deci, E. L., and R. M. Ryan. 2000. The "what" and "why" of goal pursuits: human needs and the self-determination of behavior. Psychological Inquiry 11(4):227-268. https://doi.org/10.1207/ $\underline{\text { S15327965PLI1104 } 01}$

Dercon, S., and P. Krishnan. 2000. Vulnerability, seasonality and poverty in Ethiopia. Journal of Development Studies 36(6):25-53. https://doi.org/10.1080/00220380008422653

Diener, E., S. J. Heintzelman, K. Kushlev, L. Tay, D. Wirtz, L. D. Lutes, and S. Oishi. 2017. Findings all psychologists should know from the new science on subjective well-being. Canadian Psychology/Psychologie canadienne 58(2):87-104. https://doi. org/10.1037/cap0000063

Diener, E., R. Inglehart, and L. Tay. 2013. Theory and validity of life satisfaction scales. Social Indicators Research 112(3):497-527. https://doi.org/10.1007/s11205-012-0076-y

Diener, E., S. Oishi, and R. E. Lucas. 2003. Personality, culture, and subjective wellbeing: emotional and cognitive evaluations of life. Annual Review of Psychology 54(1):403-425. https://doi. org/10.1146/annurev.psych.54.101601.145056

Diener, E., and L. Tay. 2015. Subjective well-being and human welfare around the world as reflected in the Gallup World Poll. International Journal of Psychology 50(2):135-149. https://doi. org/10.1002/ijop.12136

Ding, C., and X. He. 2004. $K$-means clustering via principal component analysis. Page 29 in ICML '04 Proceedings of the Twenty-First International Conference on Machine Learning, Banff, Alberta, Canada. Association for Computing Machinery, New York, New York, USA. https://doi.org/10.1145/1015330.1015408

Dolan, P., and R. Metcalfe. 2012. Measuring subjective wellbeing: recommendations on measures for use by national governments. Journal of Social Policy 41(2):409-427. https://doi.org/10.1017/ $\underline{\mathrm{S} 0047279411000833}$

Easterlin, R. A. 2015. Happiness and economic growth: the evidence. Pages 283-299 in W. Glatzer, L. Camfield, V. Møller, and M. Rojas, editors. Global handbook of quality of life: exploration of well-being of nations and continents. Springer, Dordrecht, The Netherlands. https://doi.org/10.1007/978-94-017-9178-6_12

Easterlin, R. A., L. A. McVey, M. Switek, O. Sawangfa, and J. S. Zweig. 2010. The happiness-income paradox revisited. Proceedings of the National Academy of Sciences 107 (52):22463-22468. https://doi.org/10.1073/pnas.1015962107

Gough, I., and J. A. McGregor, editors. 2007. Wellbeing in developing countries: from theory to research. Cambridge University Press, Cambridge, UK. https://doi.org/10.1017/ CBO9780511488986
Hektner, J. M., J. A. Schmidt, and M. Csikszentmihalyi. 2007. Experience sampling method: measuring the quality of everyday life. SAGE, London, UK.

Helliwell, J. F. 2003. How's life? Combining individual and national variables to explain subjective well-being. Economic Modelling 20(2):331-360. https://doi.org/10.1016/S0264-9993(02) $\underline{00057-3}$

Hoque, S. F., C. H. Quinn, and S. Sallu. 2017. Resilience, political ecology, and well-being: an interdisciplinary approach to understanding social-ecological change in coastal Bangladesh. Ecology and Society 22(2):45. https://doi.org/10.5751/ES-09422-220245

Hojman, D. A., and Á. Miranda. 2018. Agency, human dignity, and subjective well-being. World Development 101:1-15. https:// doi.org/10.1016/j.worlddev.2017.07.029

Hoque, S. F., C. Quinn, and S. Sallu. 2018. Differential livelihood adaptation to social-ecological change in coastal Bangladesh. Regional Environmental Change 18(2):451-463. https://doi. org/10.1007/s10113-017-1213-6

Hossain, M. S., J. A. Dearing, M. M. Rahman, and M. Salehin. 2016. Recent changes in ecosystem services and human well-being in the Bangladesh coastal zone. Regional Environmental Change 16(2):429-443. https://doi.org/10.1007/s10113-014-0748-z

Hulme, D., and A. Shepherd. 2003. Conceptualizing chronic poverty. World Development 31(3):403-423. https://doi.org/10.1016/ S0305-750X(02)00222-X

Islam, A. R. M. T., A. Tasnuva, S. C. Sarker, M. M. Rahman, M. S. H. Mondal, and M. M. U. Islam. 2014. Drought in northern Bangladesh: social, agroecological impact and local perception. International Journal of Ecosystem 4(3):150-158.

Jebb, A. T., L. Tay, E. Diener, and S. Oishi. 2018. Happiness, income satiation and turning points around the world. Nature Human Behaviour 2:33-38. https://doi.org/10.1038/s41562-017-0277-0

Jolliffe, D., and U. Serajuddin. 2018. Noncomparable poverty comparisons. Journal of Development Studies 54(3):523-536. https://doi.org/10.1080/00220388.2016.1274394

Joshanloo, M. 2019. Investigating the relationships between subjective well-being and psychological well-being over two decades. Emotion 19(1):183-187. https://doi.org/10.1037/emo0000414

Kahneman, D., and A. B. Krueger. 2006. Developments in the measurement of subjective well-being. Journal of Economic Perspectives 20(1):3-24. https://doi.org/10.1257/089533006776526030

Kahneman, D., A. B. Krueger, D. A. Schkade, N. Schwarz, and A. A. Stone. 2004. A survey method for characterizing daily life experience: the day reconstruction method. Science 306 (5702):1776-1780. https://doi.org/10.1126/science.1103572

Kahneman, D., and J. Riis. 2005. Living, and thinking about it: two perspectives on life. Pages 285-306 in F. A. Huppert, N. Baylis, and B. Keverne, editors. The science of well-being. Oxford University Press, Oxford, UK. https://doi.org/10.1093/acprof: oso/9780198567523.003.0011

Kämpfer, S., and M. Mutz. 2013. On the sunny side of life: sunshine effects on life satisfaction. Social Indicators Research 110 (2):579-595. https://doi.org/10.1007/s11205-011-9945-Z 
Khandker, S. R. 2012. Seasonality of income and poverty in Bangladesh. Journal of Development Economics 97(2):244-256. https://doi.org/10.1016/i.jdeveco.2011.05.001

MacKerron, G., and S. Mourato. 2013. Happiness is greater in natural environments. Global Environmental Change 23 (5):992-1000. https://doi.org/10.1016/j.gloenvcha.2013.03.010

Mahmud, M., and Y. Sawada. 2018. Happiness in life domains: evidence from rural Bangladesh. Pages 233-250 in Y. Sawada, M. Mahmud, and N. Kitano, editors. Economic and social development of Bangladesh: miracle and challenges. Palgrave Macmillan, Cham, Switzerland. https://doi.org/10.1007/978-3-319-63838-6 12

Mancini, A. D., G. A. Bonanno, and A. E. Clark. 2011. Stepping off the hedonic treadmill: individual differences in response to major life events. Journal of Individual Differences 32(3):144-152. https://doi.org/10.1027/1614-0001/a000047

Markussen, T., M. Fibæk, F. Tarp, and N. D. A. Tuan. 2018. The happy farmer: self-employment and subjective well-being in rural Vietnam. Journal of Happiness Studies 19(6):1613-1636. https:// doi.org/10.1007/s10902-017-9858-X

McGregor, A., S. Coulthard, and L. Camfield. 2015. Measuring what matters: the role of wellbeing methods in development policy and practice. Development Progress Project Note 4. Overseas Development Institute, London, UK.

Narayan, D., R. Chambers, M. K. Shah, and P. Petesch. 2000. Voices of the poor: crying out for change. Oxford University Press for the World Bank, New York, New York, USA. https://doi. org/10.1596/0-1952-1602-4

Nisbet, E. K., J. M. Zelenski, and S. A. Murphy. 2011. Happiness is in our nature: exploring nature relatedness as a contributor to subjective well-being. Journal of Happiness Studies 12(2):303-322. https://doi.org/10.1007/s10902-010-9197-7

Nussbaum, M. 2001. Women and human development: the capabilities approach. Cambridge University Press, Cambridge, UK.

Organisation for Economic Co-operation and Development (OECD). 2013. OECD guidelines on measuring subjective wellbeing. OECD, Paris, France. https://doi.org/10.1787/9789264191655$\underline{\text { en }}$

Paul, K. I., and K. Moser. 2009. Unemployment impairs mental health: meta-analyses. Journal of Vocational Behavior 74 (3):264-282. https://doi.org/10.1016/j.jvb.2009.01.001

Qizilbash, M. 2006. Well-being, adaptation and human limitations. Royal Institute of Philosophy Supplements 59:83-109. https://doi.org/10.1017/s1358246100009474

Rahman, S. 2000. Women's employment in Bangladesh agriculture: composition, determinants and scope. Journal of Rural Studies 16(4):497-507. https://doi.org/10.1016/S0743-0167 (00)00006-1

Rigg, J., A. Salamanca, M. Phongsiri, and M. Sripun. 2018. More farmers, less farming? Understanding the truncated agrarian transition in Thailand. World Development 107:327-337. https:// doi.org/10.1016/j.worlddev.2018.03.008
Ryan, R. M., and E. L. Deci. 2000. Self-determination theory and the facilitation of intrinsic motivation, social development, and well-being. American Psychologist 55(1):68-78. https://doi. org/10.1037/0003-066X.55.1.68

Ryff, C. D. 1989. Happiness is everything, or is it? Explorations on the meaning of psychological well-being. Journal of Personality and Social Psychology 57(6):1069-1081. https://doi. org/10.1037/0022-3514.57.6.1069

Schreckenberg, K., G. Mace, and M. Poudyal. 2018 Ecosystem services and poverty alleviation: trade-offs and governance. Routledge, Oxford, UK.

Schwanen, T., and D. Wang. 2014. Well-being, context, and everyday activities in space and time. Annals of the Association of American Geographers 104(4):833-851. https://doi. org/10.1080/00045608.2014.912549

Sen, A. 2001. Development as freedom. Oxford University Press, Oxford, UK.

Sibhatu, K. T., and M. Qaim. 2017. Rural food security, subsistence agriculture, and seasonality. PLoS ONE 12(10): e0186406. https://doi.org/10.1371/journal.pone.0186406

Sraboni, E., H. J. Malapit, A. R. Quisumbing, and A. U. Ahmed. 2014. Women's empowerment in agriculture: what role for food security in Bangladesh? World Development 61:11-52. https://doi. org/10.1016/j.worlddev.2014.03.025

Teschl, M., and F. Comim. 2005. Adaptive preferences and capabilities: some preliminary conceptual explorations. Review of Social Economy 63(2):229-247. https://doi.org/10.1080/0034676$\underline{0500130374}$

Tugade, M. M., B. L. Fredrickson, and L. Feldman Barrett. 2004. Psychological resilience and positive emotional granularity: examining the benefits of positive emotions on coping and health. Journal of Personality 72(6):1161-1190. https://doi.org/10.1111/ j.1467-6494.2004.00294.X

World Bank Group. 2016. Dynamics of rural growth in Bangladesh: sustaining poverty reduction. World Bank, Washington, D.C., USA. https://doi.org/10.1596/24369 